Marín García, Teresa.

Profesor Contratado Doctor, Universidad Miguel Hernández de Elche, Departamento Arte, Laboratorio de Interferencias Artísticas y Mediales (IAMLab)

Salom Marco, Enrique.

Historiador y Gestor cultural. Estudiante del Master Técnicas Avanzadas de Investigación Histórica. UNED.

\title{
Afectos y resistentes. Un proceso transmedia sobre experiencias de resistencia cultural cotidiana.
}

\author{
TIPO DE TRABAJO
}

Comunicación.

PALABRAS CLAVE

Resistencia cultural, afectos, memoria, archivo audiovisual, transmedia.

KEY WORDS

Cultural resistance, affections, memory, audiovisual file, transmedia.

\section{RESUMEN}

Presentamos Afectos y Resistentes, una propuesta artística transmedia en proceso abierto, que muestra varias historias cotidianas de resistencia cultural frente a políticas globalizadoras. El proyecto se inicia a partir del registro documental audiovisual de casos que suceden en nuestro entorno cercano, personas o colectivos, que realizan actividades vinculadas a la cultura en situaciones adversas o acciones en defensa de patrimonios culturales amenazados. Todos estas situaciones tienen como motor de su resistencia lo afectivo y lo vivencial. Nos interesa de estas historias su potencial narrativo para reflejar diversas problemáticas biopolíticas. La propuesta se define como transmedia porque trata de explorar distintas formas narrativas a través del diálogo entre diversos medios y espacios que se complementan (vídeos, archivos sonoros, relatos, cartografías e instal-acciones). El proyecto se estructura a partir de un archivo multimedial vinculado a una plataforma web. La plataforma web se concibe como soporte y como dispositivo de navegación entre fragmentos narrativos multimediales. El archivo es concebido como una herramienta "soporte de memoria" que permite la diversificación de voces y la construcción de múltiples narrativas no-lineales. Los registros documentales se plantean desde una mirada conscientemente subjetiva y con la intención de mostrar aspectos cercanos y detalles que puedan interpelar al espectador. El proyecto se plantea como una reflexión sobre lo experiencial y la memoria. El diálogo realvirtual nos permite explorar conflictos y posibilidades de lo audiovisual y el archivo como herramientas críticas de registro de experiencia y construcción de memoria colectiva.

\section{ABSTRACT}

We present Affections \& resistants, a transmedia art proposal in open process, showing several daily stories of cultural resistance opposing globalization policies. The project starts from an audiovisual documentary record of cases that happen in our close environment, individuals or groups that perform cultural activities in adverse situations, or perform actions in defense or protection of endangered cultural heritage. Affective and experiential factors are set at the origin of this resistance. We are interested in the narrative potential of these stories so they may show a number of bio-political problems. The proposal is defined as transmedia because it aims to explore different narrative forms through dialogue between different complementary media and spaces (videos, audio files, stories, cartographies and instal-actions). The project proposes a structure that links a multimedial file to a web platform. The web platform is conceived as a medium and as a device for browsing multimedia narrative fragments. The file is designed as a "medium memory" tool allowing 
diversification of voices as well as the building of multiple non-linear narratives. The documentary records are made from a consciously subjective look and with the aim of showing close aspects and details that may question the viewer. This project is also proposed as a reflection on experience and memory. The real-virtual dialogue allows us to explore conflicts and possibilities of audiovisual material, such as files. Also, files are deemed as critical tools for the registration of experience and construction of collective memory.

\section{CONTENIDO}

Afectos y Resistentes es una propuesta artística transmedia en proceso abierto, en la que se muestran diversas historias cotidianas de resistencia cultural frente a situaciones concretas generadas por políticas globalizadoras. Partimos de experiencias que suceden en nuestro entorno cercano y que conocemos por vinculación directa y afectiva con las personas o colectivos que las protagonizan. Más que un proyecto definido a priori lo consideramos un proceso abierto, que se va construyendo en el tiempo y que nos permite ir experimentando diversas formas narrativas desde lo visual, lo sonoro y lo textual. A partir de lo experiencial nos interesa indagar en diversas formas de tránsitos entre medios, entre lo físico y lo virtual, lo analógico y lo digital. Los objetivos de este proyecto son visibilizar pequeñas historias cotidianas de resistencia, experimentar con diversas formas narrativas para construir memoria colectiva a partir del registro de memorias vivas, y propiciar encuentros, interacciones y experiencias.

\section{Des-aprender como punto de partida}

La propuesta que presentamos se inició en 2013 como una pequeña acción sin nombre, no empezó queriendo ser un proyecto, sino más bien un proceso abierto a la experimentación que va tomando forma en el hacer. Un hacer reflexivo y con conciencia crítica frente a lo que queremos mostrar y a cómo lo queremos contar.

Se inició de modo informal, a partir de una conversación de bar a la salida de un pequeño cine de pueblo, al que solíamos ir en Alfás del Pi (Alicante), cuando teníamos oportunidad. Un cine que sobrevivía programando cine de autor fuera de los circuitos culturales, gracias al amor al cine que profesan sus propietarios.

Ese día, en ese momento de ocio, fuera de la inercia de la rutina, decidimos que podía ser interesante contar la pequeña historia de supervivencia de ese cine, como ejemplo de otros espacios similares que sobreviven manteniendo una actividad a contratiempo de los intereses imperantes del sistema neoliberal y la globalización mediática. Decidimos hacerlo y que no lo postergaríamos, que empezaríamos al día siguiente y que lo haríamos con nuestros propios medios, con los que contábamos entonces, sin depender de otros colaboradores, ni esperar subvenciones o financiación externa. Intentaríamos contar aquella historia desde nuestra subjetividad, con nuestros escasos medios, desde nuestras carencias y limitaciones, como un ejercicio de auto-aprendizaje y reflexión. Nos propusimos explorar en el propio proceso la forma misma de cómo podía ser contado, construido, compartido. Nos plantemos el juego de aventurarnos a coger una cámara para documentar acciones en proceso, sin preparación previa, interactuando con lo que pudiera pasar, receptivos a los pequeños instantes. Empezamos deliberadamente a jugar con lo básico, a contar de forma casi naif una historia cercana. Empezamos a aventurarnos en terrenos en los que nunca habíamos trabajado como era el campo de lo sonoro.

En ese momento nos interesaba sobre todo la idea de desaprender y pensábamos en referentes que habían indagado en los procesos de forma muy primaria o se habían interesado por los desaprendizajes como medio de construir otras formas narrativas o performativas, pensábamos en Jean Vigo, Dziga Vértov, Chris Marker, Kaprow, Cage, Godard o DOGMA.

\section{Historias cotidianas de resistencia cultural frente a la globalización}

Afectos y resistentes se compone de varios proyectos específicos que se vehiculan a través de pequeñas historias de vida cotidiana. Cada una de estas historias de resistencia aborda cuestiones concretas en un contexto local específico, que pueden ser representativas de muchas otras historias similares. Las políticas neoliberales, aunque se camuflen bajo la coartada de la deslocalización se aplican de forma localizada, afectando a realidades concretas y contextos locales específicos. Por ello las respuestas defensivas siempre son de carácter local y suelen ir asociadas a un fuerte compromiso personal y colectivo. En relación con estas repuestas de resistencia localizadas nos interesa repensar el concepto de "situación". Sartre desde el existencialismo ya proponía la idea del hombre como un "ser-en-situación", que asociaba a la responsabilidad de "ser libre", la elección de los propios actos y el compromiso social. Para los situacionistas la "situación" se identifica con el "proyecto" existencial y con la dimensión de la "auténtico"; es expresión de un suceso que se manifiesta en la vida cotidiana ${ }^{1}$. Recientemente Miguel Benasayag ha definido el concepto

1 Perniola, M. Los situacionistas. Acuarela \& A. Machado, Madrid, 2010, pp. 30-31 
"situación" como "la unidad que permite volver a territorializar la vida, el pensamiento y la acción en el desgarrón de la posmodernidad"2.

El nombre genérico del proyecto Afectos y Resistentes refleja los dos aspectos fundamentales que atraviesan las distintas historias que lo conforman, generando un diálogo polisémico y abierto a múltiples niveles de lectura. Uno de ellos es la idea de resistencia, encarnada en agentes resistentes, "capaces de resistir" (DRAE, 2014) o que pertenece a la resistencia, oponiéndose a invasores o dictaduras. Todos los casos con los que se trabaja en el proyecto abordan situaciones conflictivas relacionadas con la supervivencia de actividades o profesiones en el ámbito de la cultura, o con la defensa de patrimonios culturales amenazados (sean materiales 0 inmateriales).

El otro aspecto esencial son los efectos, ya que en todas estas historias lo vivencial y lo emocional tienen un papel central como motor de resistencia. Del concepto "afectos" nos interesa su potencial de lecturas múltiples. Por una parte su sentido emocional, relacionado con "las pasiones del ánimo", especialmente el amor y el cariño (DRAE, 2014), por otra la idea de aquel que sufre daño, y en sentido amplio se ve afectado, perjudicado o menospreciado. Prestar atención a lo emocional en relación a diversas temáticas de carácter socio-político y cultural nos permite reflexionar y visibilizar problemáticas biopolíticas ${ }^{3}$ y psicopolíticas ${ }^{4}$ derivadas de la expansión de los poderes del capital.

Tomamos de la posmodernidad la puesta en valor de los pequeños discurso de resistencia, pero a diferencia de la lectura posmoderna que defiende la desaparición de los grandes relatos, observamos a través del estudio de múltiples casos que la suma de estos pequeños relato podrían componer un cuadro general de resistencia local a modo de contrapoder, frente a la persistencia del gran relato del capital-imperio ${ }^{5}$. El capitalismo posfordista se caracteriza por una creciente desmaterialización de los procesos productivos, que ha conllevado el paso del trabajo "material" al "inmaterial" y un aumento de la producción de bienes inmateriales, cuyo valor simbólico prevalece sobre el valor de uso. Podemos observar en estos procesos algunos rastros del debate dialéctico de lo material y lo virtual. A pesar de ello, opinamos que lo material y lo virtual, más que pares de opuestos son realidades que conviven superpuestas e interdependientes conformando una realidad compleja.

Las historias que estamos recogiendo y los procesos con los que estamos experimentando son los siguientes: Cine Roma (2013), Llibrería Sant Jordi (2014) (en proceso), Barri Cabanyal. Redes y paseos (2014-2015) (en proceso), La Torre (2014-2015) (en proceso), Falla Arrancapins (2015) (en proceso). Cada caso refleja una situación específica que muestra respuestas y acciones localizadas en el aquí y el ahora cotidiano frente a distintas temáticas derivadas del desarrollo de modelos de producción posfordista y enfoques económico-culturales globalizadores. Como se indica en el esquema (Ilustración 1) hemos identificado algunas temáticas genéricas, representativas de las políticas neoliberales que atraviesan varias de estas historias, como son: la crisis de los modelos de producción y distribución, que afectan especialmente a sectores culturales como la edición de libros o el sector audiovisual; la gentrificación como forma especulativa de los territorios urbanos; la "turistificación" como una forma larvada de control y mercadeo económico de los espacios urbanos; y la propia globalización como una forma de deslocalización de bienes y usos de consumo.

2 Entrevista con Miguel Benasayag: "Resistir no es sólo oponerse, sino crear, situación por situación, otras relaciones sociales" 24/04/2015 [ http://m.eldiario.es/interferencias/Miguel-Benasayag-Resistir-situacion-relaciones_6_380821943.html ] [consulta: 25/04/2015]. 3 Foucault, M. Nacimiento de la biopolítica. FCE, México, 2007.

4 Han, B-Ch. Psicopolítica. Herder, Barcelona, 2014.

5 Hardt, M., Negri, A. Imperio. Paidós, Barcelona, 2005. 


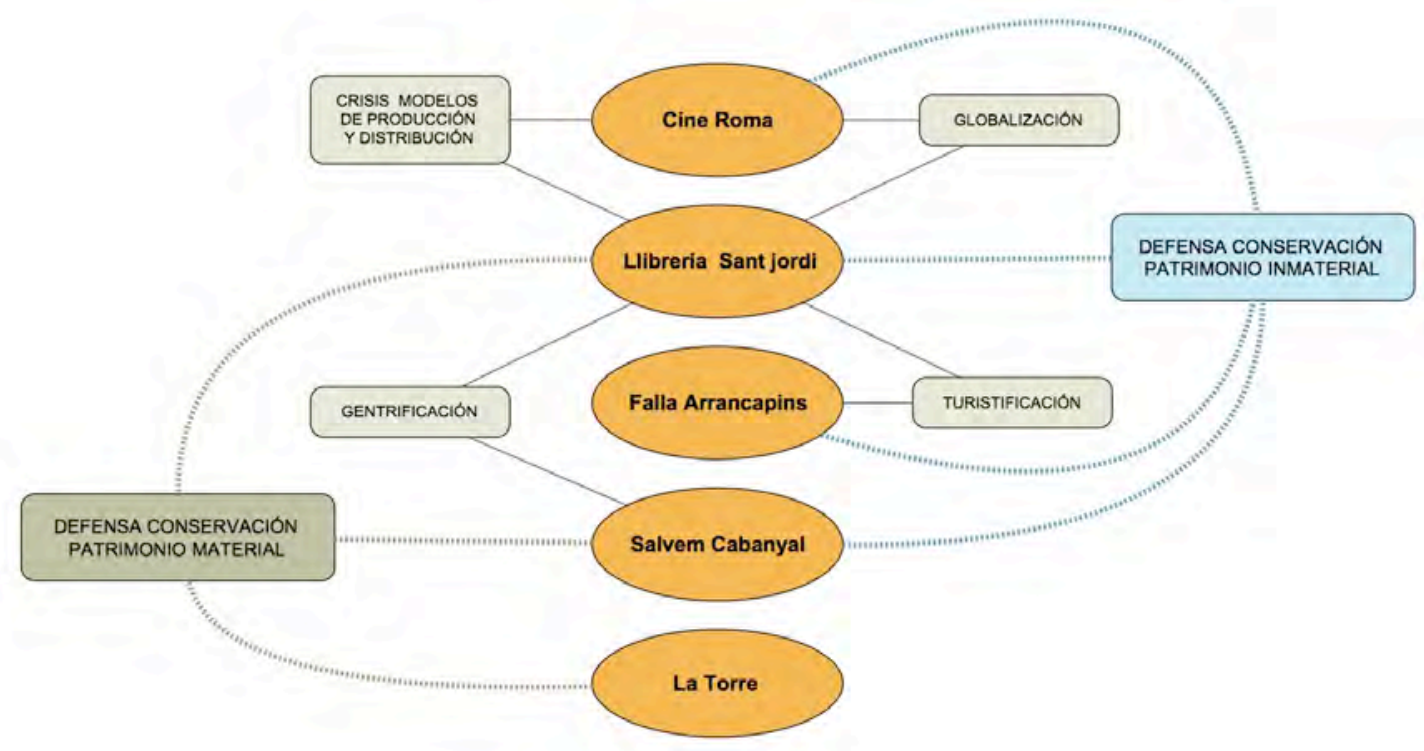

Proyecto Afectos y Resistentes: vinculos temáticos

\section{llustración 1. Proyecto transmedia Afectos y Resistentes: esquema de vínculos temáticos. Elaboración propia}

De forma transversal a las temáticas planteadas subyace la idea, de modo más o menos explícito según cada caso, de la defensa de patrimonios materiales o inmateriales, (Ilustración 1). Este sería otro aspecto de la dimensión física y virtual que contempla nuestro proyecto. En algunos casos se combinan ambos factores, como en el caso de la en la defensa del Barrio del Cabanyal, antiguo barrio marinero de Valencia amenazado de derribo desde hace más dieciséis años por un proceso de gentrificación promovido por el propio Ayuntamiento de la ciudad. Entre las 1.651 viviendas afectadas se encuentran numerosas edificaciones catalogadas por su valor patrimonial, además del valor del propio entramado social del barrio (redes de afectos). De igual modo, la Llibreria Sant Jordi es un negocio singular situado en el Barrio Gótico de Barcelona, que además de dedicar su actividad a la venta de libros, que incluye venta de ediciones descatalogadas, sus propietarios han conservado mobiliario del siglo XIX así como otras características del propio local. Este negocio sobrevive a pasar de la entrada en vigor de la $\operatorname{LAU}^{6}$ en una zona donde están despareciendo los antiguos negocios y apenas quedan librerías. En el caso de La Torre, el tema principal es la defensa de un patrimonio material en peligro de desaparición. En este caso no está en juego la supervivencia de una familia ni un barrio. Se trata más bien de un ejercicio altruista y apasionado de una persona con sensibilidad e iniciativa, que ante la dejadez institucional y de los propios propietarios de una torre defensiva del s. XVI-XVII, decidió comprarla en los años 70 y restaurarla él mismo, con escasos recursos y ayuda de amigos, a la vez que realizaba trabajos de catalogación y visibilización de patrimonio similar en toda la provincia de Castellón. En el caso de la Falla Arrancapins se plantea la defensa de un patrimonio inmaterial que indaga en la investigación y acción participativa para la recuperación de aspectos esenciales del origen de la fiesta de las fallas. Por último, el caso del Cine Roma plantea la supervivencia de un antiguo cine de pueblo en una zona donde apenas quedan cines, que sobrevive programando cine de autor y versión original.

\section{Procesos: de la experiencia a la memoria compartida}

Como apuntamos al inicio planteamos esta propuesta como un proceso abierto de acción y reflexión. En la llustración $\mathbf{2}$ mostramos de forma esquemática algunos de los elementos fundamentales de este proceso de construcción de memoria compartida a partir de la experiencia y en el que el registro, el archivo y las narrativas transmedia constituyen "ArteFactos" esenciales del proceso.

6 LAU. Ley de Arrendamientos Urbanos, 29/1994, BOE del 24 de noviembre de 1994. Esta ley entró en vigor el 1 de enero de 2015 y supone la actualización de alquileres de renta antigua a precios de mercado lo que supone de facto la desaparición de comercios tradicionales de las centros urbanos y zonas revalorizadas por procesos gentrificadores y de turistificación. 


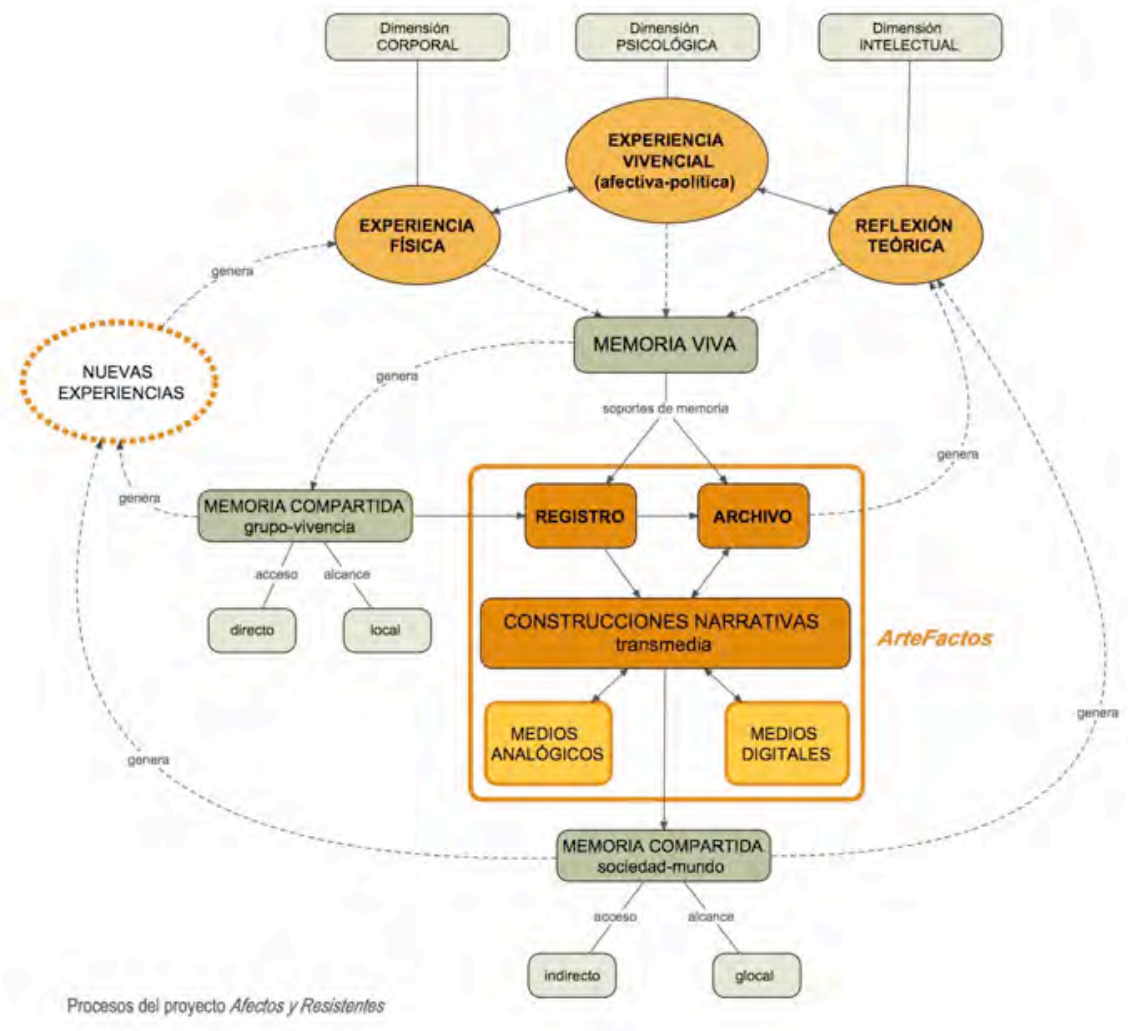

llustración 2. Proceso dinámico del proyecto transmedia Afectos y Resistentes: aspectos físicos y virtuales. Elaboración propia

Como antes ya mencionamos apostamos por una concepción de la realidad compleja y multidimensional, de ahí que tengamos en cuenta como punto de partida las distintas dimensiones que constituyen la experiencia: corporal, psicológica e intelectual. Las experiencias físicas (sensoriales), vivenciales (afectivo-políticas) y la reflexión, son nuestro material primario. A través de ellas generamos un registro y archivo de memoria viva de los protagonistas de las historias que nos interesan. Diferenciamos dos recorridos para la construcción de memoria compartida ya que pensamos que posibilitan diferentes resultados y usos. Por una parte, la transmisión de dicha memoria viva de los protagonistas de las pequeñas historias de resistencia en sus contextos cercanos que de forma directa generan ya una construcción de memoria compartida. Esta memoria compartida constituye tanto un material susceptible de ser reelaborado como construcción narrativa de experiencias, como referente o punto de partida de nuevas experiencias comunitarias o individuales. Por otra parte, todos los materiales susceptibles de ser registrados, archivados y recreados de forma narrativa pueden llegar a constituir otra forma de memoria compartida, que a través de distintos medios pueden tener una alcance más global a otras contextos. En ese proceso expansivo de carácter indirecto pueden generarse pequeñas metamorfosis, hibridaciones y nuevas sugerencias de sentido. El proceso en su conjunto se concibe como un flujo susceptible de posibilitar una retroalimentación, que permita nuevas experiencias.

\section{ArteFactos narrativos}

Bajo el nombre genérico de "ArteFactos" consideramos los tres recursos esenciales de nuestro proyecto: el registro, el archivo y las narrativas transmedia. Los consideramos interdependientes entre sí para potenciar las capacidades narrativas de los materiales generados. Con el término "ArteFactos" queremos destacar por una parte la importancia del hacer, de la acción y que partimos de "hechos" así como el múltiple juego de palabras que produce, un artefacto es tanto una máquina o aparto mecánico "hecho con arte" (DRAE, 2014), como un material explosivo. También nos interesan acepciones menos conocidas del término que se aplican a los campos de la biología o la medicina y que indican la perturbación de la interpretación de resultados o las "variaciones no originada por el órgano cuya actividad se desea registrar"(DRAE, 2014).

Uno de los elementos clave de esta propuesta es el registro visual y sonoro, que lo entendemos tanto como un soporte de memoria como un recurso narrativo. Hacemos la distinción explicita de lo visual y sonoro de forma separada, (y no como audiovisual) porque nos interesa dar relevancia a ambos aspectos por igual y que puedan también operar de manera independiente y autosuficiente. En nuestro proceso experimental ambos aspectos están siendo trabajados de forma relacionada pero con atención individualizada, intentando explorar sus distintas cualidades sensoriales. 
Un aspecto que nos parece reseñable respecto al registro es el deliberado posicionamiento subjetivo de la mirada. En este sentido hay una apuesta activa por distanciarnos del documentalismo periodístico o de corte objetivo. Hay una toma de partido metodológica que se define a partir de los presupuestos planteados por Donna Haraway sobre el "conocimiento situado" ${ }^{7}$ asumiendo que el espectador nunca es neutral y que el lenguaje audiovisual construye discurso.

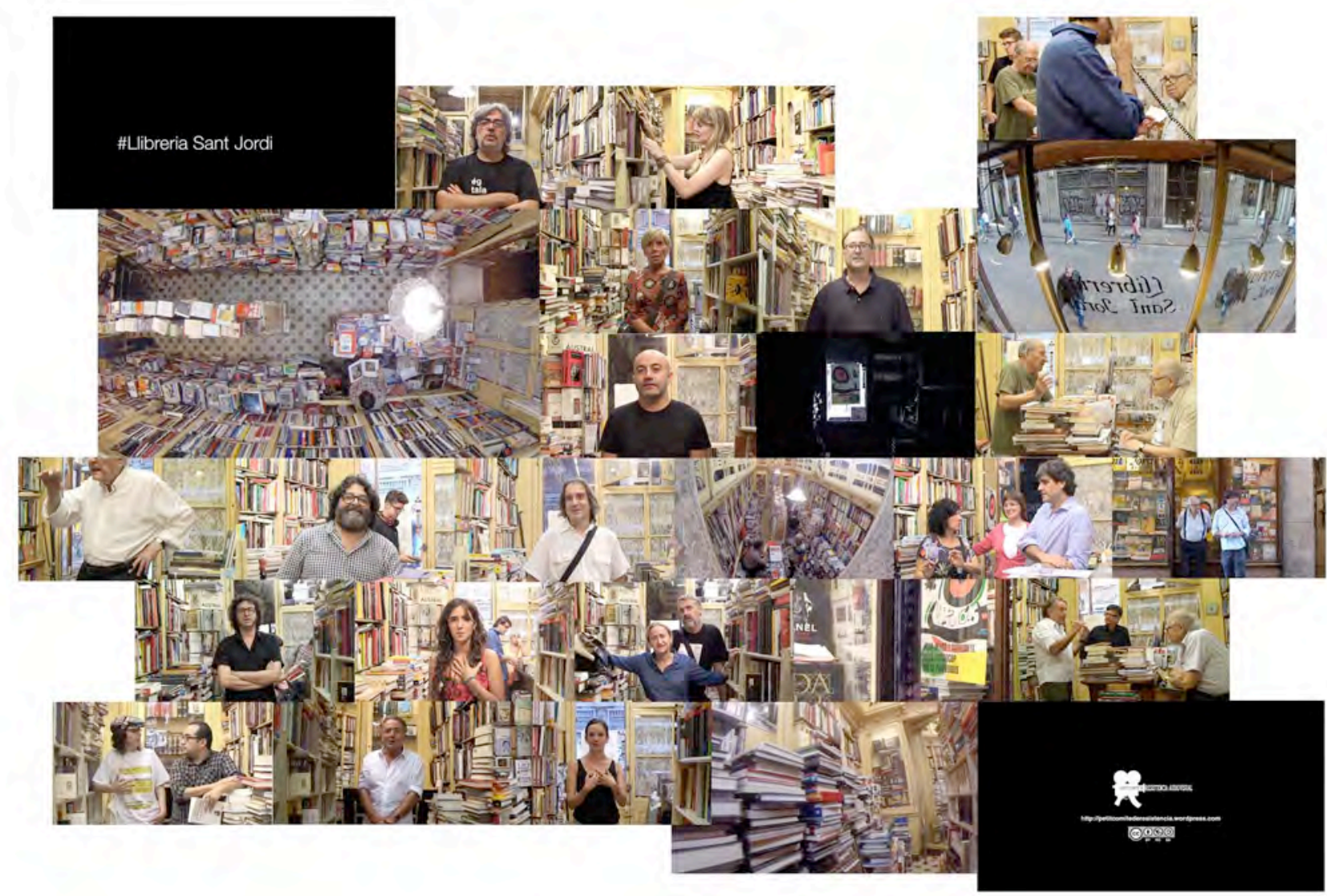

Ilustración 3. Imágenes del proyecto Llibreria Sant Jordi (2014-15). Una de las historias de Afectos y Resistentes.

Lo experimental y procesual son aspectos clave en la concepción del proceso de registro, que condiciona el posterior montaje. intentamos no ir con demasiadas ideas preconcebidas, ni proyectadas. Tratamos de dejarnos afectar por los lugares y las personas con las que vivimos estos procesos. Generalmente partimos de un conocimiento previos de lugares y al menos de los protagonistas principales, pero la idea acerca del lugar y la situación es más de encontrar que de buscar, de atender al "aquí" y "ahora" más que un resultado planificado. El proceso de registro, de (re)descubrir el espacio y las personas, es en sí mismo parte de la experiencia de interrogarnos sobre cómo contar esa historia. Proceso que podría entenderse como observación participante, ya que hacemos evidente nuestra presencia y compromiso en aquellos temas que estamos registrando, improvisando en ocasiones el rol de "etnógrafos amateurs".

Nos interesa especialmente profundizar en las fuentes orales y en la visualidad gestual, como narrativa subjetiva sea individual o colectiva. El registro visual y sonoro cumple la función de una oralidad aumentada.

El archivo se aloja en la plataforma Web del proyecto ${ }^{8}$. Definimos el archivo como nómada porque surge y refleja contextos localizados a los que nos vamos desplazando y porque su ubicación en la red permite una recontextualización múltiple y cambiante. Entendemos el archivo como soporte de huellas y fragmentos de memoria: dejar constancia de pequeñas historias de resistencia como formas de conservar experiencias y testimonios para visibilizar saberes poco valorados, no imperantes ni normativos. Se plantea la necesidad de preservar saberes considerados menores ${ }^{9}$ e interrogar sobre distintas formas de poder/opresión hegemónicas,

7 Haraway, D. Ciencia, cyborgs y mujeres: la reinvención de la naturaleza. Universitat de València, Valencia, 1995. 8 Url del proyecto Afectos y Resistentes: https://petitcomitederesistencia.wordpress.com/.

9 Hacemos mención a los "saberes menores" según acepción de Foucault. Foucault, M. Microfísica del poder. Las Ediciones de La Piqueta, Madrid, 1992 
invisibilizadas por su ubicuidad y discurso totalizador. En estos debates se hace patente el conflicto permanente ente lo local y lo global.

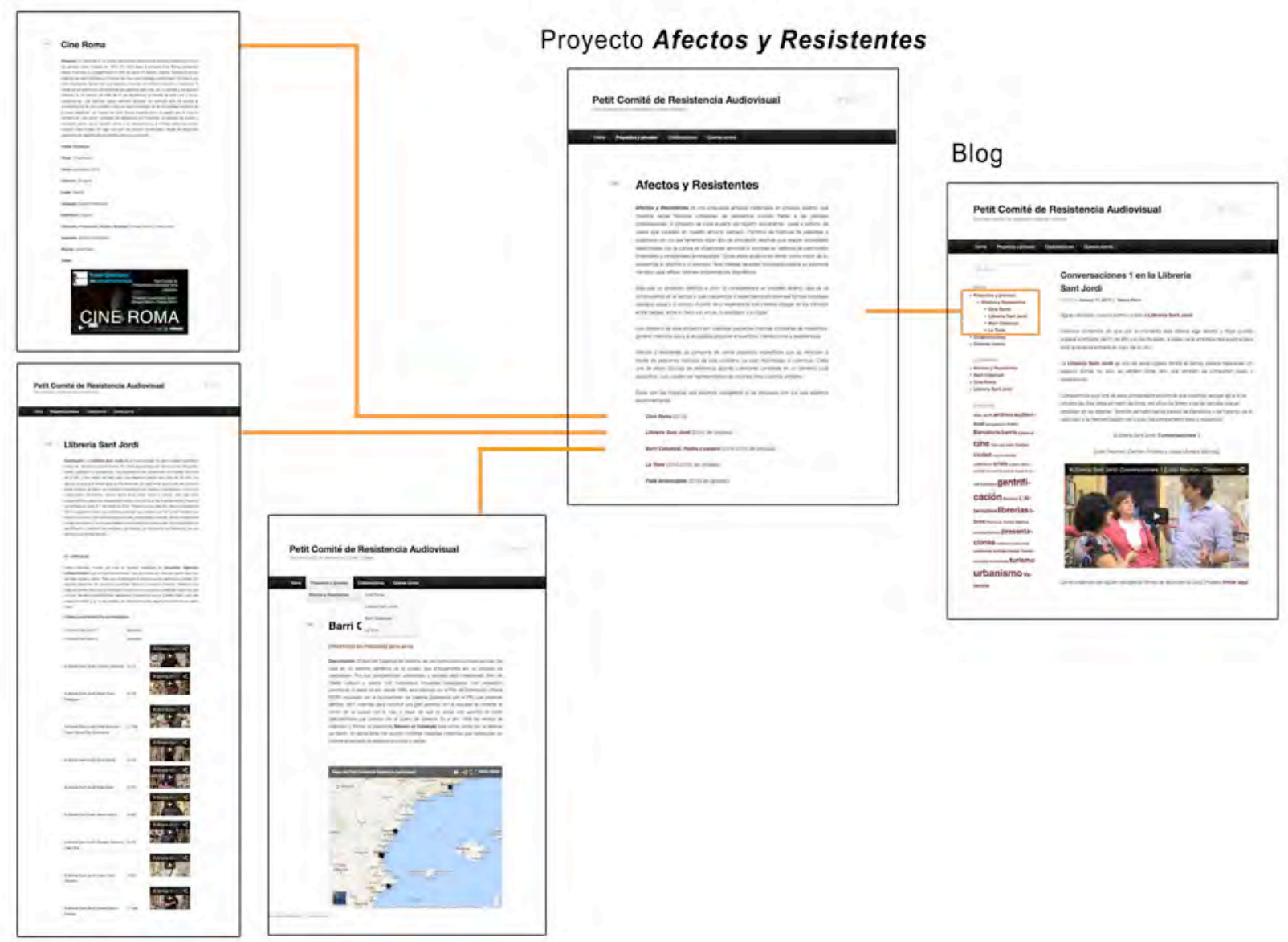

Ilustración 4. Estructura de la plataforma web del proyecto Afectos y Resistentes.

La elección del archivo se inscribe en la tradición de referentes previos ${ }^{10}$. Nos interesa del archivo su capacidad de "soporte de memoria" (hypomnesis), que no se debe confundir con la memoria (mneme), ni con la rememoración o recuerdo voluntario (anamesis) como precisaba Derrida (1997) ${ }^{\mathrm{i} 11}$. Conscientes que el usuario del archivo siempre es alguien por-venir (Derrida, 1997) y que hará uso de esas huellas desde su presente, siendo impredecible y pudiendo llegar incluso a su destrucción. Jugamos por tanto con esta idea como potencial procesual y abierto.

Por último, mencionar que esta propuesta esta pensada en clave transmedia con el objetivo de experimentar y potenciar diversas posibilidades de narraciones múltiples y no lineales. En este sentido nos interesan especialmente los tránsitos y diálogos que se puedan generar entre los desarrollos de una misma historia a través de medios distintos. También explorar el potencial que pueden aportar al relato tanto los medios físicos como los virtuales, la suma de ambos componen una experiencia más rica y "real" de lo que entendemos hoy como experiencia de vida en oposición a la experiencia debida. La doble naturaleza real-virtual está en la esencia de las temáticas y conflictos que plantea este proyecto. Nos interesa de lo transmedia su potencial narrativo para activar y entrecruzar voces distintas y diversos tratamientos, en unos casos más descriptivos y reflexivos, en otros más poéticos y sensoriales. En los último proyectos estamos trabajando de forma más atenta para mostrar esa multiplicidad de lecturas, que consideramos necesario combinar y mostrar juntas para sugerir la complejidad de las experiencias de vida de las que partimos, que como se mencionó son multidimensionales (física, psicológica e intelectual). En definitiva queremos compartir la complejidad de la experiencia a través de la memoria compartida generada por redes afectivas, experiencia que hibrida múltiples dimensiones de la "realidad" (<|real| virtual|>).

10 Guasch, A. M. Arte y archivo, 1920-2010. Genealogías, tipologías y discontinuidades. Akal, Madrid, 2011.

11 Derrida, J. Mal de archivo. Una impresión Freudiana. Trotta, Madrid, 1997. 


\section{FUENTES REFERENCIALES.}

Afectos y Resistentes. https://petitcomitederesistencia.wordpress.com/. [consulta: 28/04/2015].

Derrida, J. Mal de archivo. Una impresión Freudiana. Trotta, Madrid, 1997.

Entrevista con Miguel Benasayag: "Resistir no es sólo oponerse, sino crear, situación por situación, otras relaciones sociales" 24/04/2015 [ http://m.eldiario.es/interferencias/Miguel-Benasayag-Resistir-situacion-relaciones_6_380821943.html ] [consulta: 25/04/2015].

Foucault, M. Microfísica del poder. Las Ediciones de La Piqueta, Madrid, 1992.

Foucault, M. Nacimiento de la biopolítica. FCE, México, 2007.

Guasch, A. M. Arte y archivo, 1920-2010. Genealogías, tipologías y discontinuidades. Akal, Madrid, 2011.

Han, B-Ch. Psicopolítica. Herder, Barcelona, 2014.

Haraway, D. Ciencia, cyborgs y mujeres: la reinvención de la naturaleza. Universitat de València, Valencia, 1995.

Hardt, M., Negri, A. Imperio. Paidós, Barcelona, 2005.

LAU. Ley de Arrendamientos Urbanos, 29/1994, BOE del 24 de noviembre de 1994.

Perniola, M. Los situacionistas. Acuarela \& A. Machado, Madrid, 2010, pp. 30-31. 